Varia 



\title{
El delirio frente a la razón en el Quijote
}

\author{
Juan Vadillo
}

El artículo gira en torno a la tensión contrapuntística que crea el delirio frente a la razón en el Quijote. Partimos de la idea (que compartimos con María Zambrano) de que el delirio es una forma de inteligencia diferente a la inteligencia racional, y que es también una de las diferentes perspectivas (de acuerdo con Leo Spitzer) que conforman el mundo. Es el espacio de la metáfora, de la invención, de la alucinación, es el mundo de don Quijote. Nuestro caballero andante intentará verter su mundo sobre la realidad racional y allí se generará el enfrentamiento entre el delirio y la razón, en términos contrapuntísticos, la disonancia que se resuelve en consonancia casi siempre cuando es derrotado el delirio; en ese momento se acaba el tiempo sin tiempo de la aventura, y don Quijote vuelve al tiempo cronológico y distingue la realidad racional, pero no podrá aceptarla, a menos que esté encantada.

Este tema es analizado a la luz de diversas obras, entre ellas: La ambigüedad en el Quijote de Manuel Durán; "Don Quijote" de Foucault; Meditaciones del Quijote, de Ortega y Gasset; "Ambigüedad de la novela", de Octavio Paz; "Perspectivismo lingüístico en El Quijote", de Leo Spitzer, etc.

Palabras Clave: Quijote, locura, razón, realidad.

This article revolves around the counterpoint tension that is created by delirium in the face of reason in the Quixote. We begin with the idea (which we share with María Zambrano) that delirium is a different kind of intelligence from rational intelligence, and that it is also one of the many different perspectives (according to Leo Spitzer) that make up the world. It is the space of metaphor, of invention, of hallucination; it is the world of Don Quixote. Our errant knight will attempt to pour his world over rational reality, and that is where the clash of delirium and reason will be produced in counterpointing terms, the dissonance that is almost always resolved into consonance when delirium is 
defeated; in this moment, the time without time of the adventure ends, Don Quixote returns to chronological time and distinguishes rational reality, but will be unable to accept it unless it is enchanted.

This subject is analyzed in the light of several works, among them: La ambigüedad en el Quijote, by Manuel Durán; "Don Quijote" by Foucault; Meditaciones del Quijote, by Ortega y Gasset; "Ambigüedad de la novela", by Octavio Paz; "Perspectivismo lingüístico en El Quijote", by Leo Spitzer, etc.

Keywords: Don Quixote, madness, reason, reality.

Fecha de recepción: 4 de agosto de 2012

Fecha de aceptación: 13 de julio de 2013 
Juan Vadillo

Universidad Nacional Autónoma de México

Facultad de Filosofia y Letras

\section{EI delirio frente a la razón en el Quijote}

Se equivocó la paloma.

Se equivocaba.

Por ir al Norte, fue al Sur.

Creyó que el trigo era agua.

Se equivocaba.

Creyó que el mar era el cielo; que la noche, la mañana. Se equivocaba.

Rafael Alberti, Se equivocó la paloma

\section{Introducción}

En su libro, El pensamiento de Cervantes, Américo Castro apuntaba que el autor del Quijote "es un racionalista que nos da los límites de lo racionalmente estructurable" (53). Por otro lado, María Zambrano había señalado que "la relación inicial, primaria, del hombre con lo divino no se da en la razón, sino en el delirio" (Hombre y divino, 28). Esta distinción (entre delirio y razón) supone que el delirio es una manera de conocer el mundo, y por lo tanto existe una inteligencia delirante. 
En cuanto empezamos a percibir con esta inteligencia rebasamos los límites de lo racionalmente estructurable.

Cervantes comienza a explorar los límites de la razón desde la razón. Emprende una lucha dialéctica ente delirio y razón. Para Ciriaco Morón Arroyo se trata de "un experimento más allá de los límites de la razón" (Nuevas meditaciones, 207). Este mismo autor advierte que "sólo quien explora los límites de la razón puede llegar a ensancharlos" (212). Alfonso Reyes refiriéndose a la frontera entre la locura y la cordura escribe que "por esa indecisa frontera anduvo vagando muchas veces el pensamiento de Cervantes" ("El enigma de don Quijote", 57).

En el discurso de la Edad Dorada, don Quijote nos habla de una época en la que "aún no se había atrevido la pesada reja del corvo arado a abrir ni visitar las entrañas piadosas de nuestra primera madre" (I, 11, 97-98). Esta imagen bien podría representar a la razón arando la tierra primigenia del delirio, creando surcos que también son fronteras. El mundo delirante es como una tierra sin arar donde el universo se percibe como un todo. Nietzsche habla de lo misterioso Uno primordial; Octavio Paz, de la analogía. Nos invitan a imaginar un tiempo y un espacio que no habían sido delimitados por la razón; un instante y un lugar sin medidas ni escisiones. El principio de la razón es justamente medir y escindir para conocer, para darles nombre a las cosas; conforme la razón avanza en la historia, el mundo delirante se desvanece. En una sociedad fundada en el análisis y la razón, el mundo delirante aparece como un sustrato oculto detrás de los límites y de los nombres. De pronto un loco o un poeta lo descubre; intuye que los entes más disímiles pueden ser idénticos, ya que alguna vez fueron parte del todo. La metáfora vuelve a unir lo que había sido escindido; la palabra, que había sido el instrumento de la razón, es ahora aliada del delirio. "Las más mínimas analogías [advierte Foucault refiriéndose a don Quijote] son solicitadas como signos adormecidos que deben ser despertados para que empiecen a hablar de nuevo" ("Don Quijote", 54). Don Quijote "conduce la analogía hasta la identificación total" (Redondo, Otra manera, 330). Hasta la identidad más profunda del mundo primordial. Este proceso analógico - de acuerdo con Augustin Redondo- "subraya cuan diferente de la lógica racional es la del héroe cervantino. Esa 
'razón de la sin razón', ${ }^{1}$ que conduce a otra concepción del mundo, no puede haber nacido sino en la cabeza de un loco" (330).

La concepción del mundo del Quijote - creemos - se construye merced al antagonismo entre la lógica racional y la lógica delirante. Allí es donde se ensanchan las fronteras de la razón, también las del delirio. Habíamos hablado de una lucha dialéctica que emprende Cervantes desde su postura racional, su punto de partida. Nos parece que el resultado de esta lucha es una suerte de contrapunto a dos voces, que rebasa la mera noción de razón y delirio (aunque parte de ella) para mostrarnos el mundo como un dejar de ser siendo, como el movimiento de las voces, palabra en el tiempo. Allí la locura igual que la razón es porque deja de ser. Contrapunto es tensión y relajación, disonancia y consonancia, tesis y antítesis, disoluciones y resoluciones, engaño y desengaño, perpetua metamorfosis, un caleidoscopio invisible que transforma la realidad a cada pulso. En el contrapunto de la música la disonancia es la tensión que crean dos notas antagónicas o dispares, esta tensión se resuelve en el siguiente pulso con dos notas consonantes o afines que transforman la tensión en relajación. En la literatura moderna el contrapunto puede verse como "un texto hecho de oposiciones que se resuelven en consonancias" (Paz, Hijos de Limo, 380). Américo Castro advierte que "ya no es un lugar común que Cervantes tome la idea de armonía y disonancia y la lleve no al mundo objetivo, sino a la relación del sujeto y el objeto" (Pensamiento de Cervantes, 39), es decir, que lleve la idea de armonía y disonancia al problema de la realidad. Acaso la realidad en el Quijote no implica una suerte de contrapunto entre el sujeto y el objeto. El contrapunto es también confrontación, comparación y contraste. De acuerdo con Américo Castro, "si hay en Cervantes una preocupación máxima, sería la de expresar literariamente el contraste entre las imaginaciones extraordinarias y fantásticas y la experiencia común y usual" (82). Recordemos que don Quijote había dicho "que todo este mundo es máquinas y trazas, contrarias unas de otras" (II, 29, 777). Pedro Salinas nos invita a pensar que Cervantes no hace a su personaje, sino que lo va deshaciendo, eso le da a don Quijote "su tensión agónica, su razón

\footnotetext{
${ }^{1}$ Esta frase (que tan inteligentemente usa Redondo) aparece en el Quijote (I, 1, 29) cuando el narrador se burla del estilo intrincado de Feliciano de Silva.
} 
de vida, que es la contradicción y lucha entre cuerdas palabras y actos locos, la sensatez de sus discursos y la insensatez de sus arremetidas" ("Cervantes", 120). Es muy importante recordar que el contrapunto no sólo es la antítesis, sino también su resolución: a veces una simbiosis, a veces la derrota, otras la máxima consonancia de la muerte, que va adquiriendo diferentes rostros hasta llegar a su culminación en el último capítulo.

En el Quijote, el contrapunto es sincronía y diacronía, metáfora y metonimia, expresión de una realidad que se despliega en el tiempo para dejar de ser, encantada y desencantada, para que podamos observarla desde todos los puntos de vista. Expresión de otra realidad prisionera en un instante.

\section{La realidad}

En el primer párrafo del capítulo décimo de la segunda parte, el narrador del Quijote advierte:

Llegando el autor de esta grande historia
a contar lo que en este capítulo cuenta,
dice que quisiera pasarle en silencio,
temeroso de que no había de ser creído,
porque las locuras de don Quijote llegaron
aquí al término y raya de las mayores
que pueden imaginarse, y aún pasaron
dos tiros de ballesta más allá de las mayores (613-614).

Curiosamente en este capítulo las locuras de don Quijote serán mínimas; a la hora de mirar a las tres labradoras su apreciación se ajustará totalmente a lo que llamamos realidad. Será su escudero quien, esta vez (invirtiendo los papeles), defienda la fantasía al intentar engañar a su amo y convencerlo de que una de ellas es la bella Dulcinea.

Nos interesa resaltar que más allá de la ironía, lo que podría estar sugiriendo el narrador en este primer párrafo es que no hay mayor locura que la misma realidad. Esta sugerencia nos invita a preguntarnos 
qué es la realidad: acaso hay una sola o muchas, está fuera o dentro de nosotros.

El problema de la realidad en el Quijote ha sido estudiado por Ortega y Gasset en sus Meditaciones del Quijote (1914). Intentaremos esbozar someramente algunas de sus ideas. El filósofo distingue entre dos realidades, una llamada "objetividad", conformada por todas las diversas interpretaciones que podamos hacer de una sola cosa, y otra llamada "real", que es la cosa en sí. Los puntos de vista subjetivos se condensan conformando la "objetividad", que entraña la idea o sentido, mientras que la otra realidad ("real") entraña la materialidad. Ambas se enfrentan en un perenne conflicto: cuando triunfa la idea o sentido vivimos alucinados; cuando gana la materialidad vivimos desilusionados (observemos cómo esta idea puede ajustarse a nuestra noción de contrapunto: el enfrentamiento es el momento de la disonancia, y el triunfo de alguna de las partes, el de la consonancia; a su vez la "objetividad" se ajusta al delirio, ya que éste — en su sentido primordial — entraña todas las voces). El Ser es esencialmente una perspectiva, una relación entre lo "real" y el punto de vista que conforma (con todas los puntos de vista) la "objetividad". Para Ortega y Gasset el realismo y el idealismo no son sino puntos de vista, perspectivas, interpretaciones. Así mismo la imaginación y la fantasía son dimensiones que conforman la "objetividad" (219-220).

Décadas después, Leo Spitzer, en su ensayo "Perspectivismo lingüístico en el Quijote" (1948), no sólo enriquecerá las ideas de Ortega y Gasset, sino que también aportará nuevas, en lo que se refiere al problema de la realidad. Spitzer advierte que el perspectivismo estructura la novela en su conjunto. Los puntos de vista crean un juego dialéctico que nos deja ver los "múltiples aspectos de un problema debatido" $(162,191)$. La novela, que es palabra en el tiempo, se estructura y desestructura - creemos - merced a este juego dialéctico (se trata de una polifonía estructurada por medio del contrapunto).

En este sentido Claudio Guillén advierte que "la presentación de la abundancia del mundo" - en el Quijote - se debe al dialogismo y al perspectivismo ("Cauces de la novela", 1145). Guillén no se refiere a la realidad sino al mundo (en general Spitzer hace lo mismo). En su recorrido, de aventura y desventura, don Quijote va descubriendo las 
diferentes realidades que conforman el mundo. Cada punto de vista, que se hace y se deshace mediante el diálogo, puede entrañar una realidad. Así, el mundo puede entenderse como la "objetividad" de Ortega, condensación de todos los puntos de vista, siempre y cuando se incluya en él la materialidad de la que parten las perspectivas. Spitzer señala que "si una cosa me parece a mí como $a$ y a ti como $b$ puede ser que en realidad no sea ni $a$ ni $b$, sino $a+b$ " ("Perspectivismo lingüístico", 199). El baciyelmo conforma la "objetividad" de Ortega, condensando dos puntos de vista que reflejan dos realidades. Los molinos de viento, no son molinos ni son gigantes, son molinos y son gigantes (Paz, "Ambigüedad de la novela", 223).

Ahora bien, si observamos la relación entre el sujeto y la materialidad, nos sorprende la riqueza interior de los personajes. Allí es donde se cocinan las diferentes versiones del mundo. "Contemplamos las figuras literarias - apunta Américo Castro- tanto hacia dentro como hacia fuera de ellas, como resultado de una introspección y 'extrospección' simultáneas" (Hacia Cervantes, 309). En la percepción racional, el mundo interior intenta ajustarse a la materialidad (medirla, delimitarla, nombrarla), que la razón denomina realidad objetiva.

Octavio Paz al referirse al Quijote señala que "el realismo de la novela es una crítica de la realidad y hasta una sospecha de que sea tan irreal como los sueños y fantasías de don Quijote" ("Ambigüedad de la novela", 223). Américo Castro habla de una actitud crítica frente a lo real (Pensamiento de Cervantes, 87). Paz se refiere a una realidad racional (objetiva) frente a otra delirante, a la que pertenecen los sueños y las fantasías de don Quijote. Las diversas realidades que conforman el mundo - creemos - o bien tienen un sentido racional, o bien delirante (esta orientación no impide que cada una de las realidades sea única, ya que entraña la visión del sujeto). Podemos hablar de contrapunto entre el sentido racional y el delirante, porque al confrontar la razón frente al delirio se crean oposiciones binarias (mesura-desmesura; precisión - vaguedad; lucidez-embriaguez; vigilia - sueño; coherencia-incoherencia; claridad-alucinación, escisión-totalidad; tiempo cronológico-tiempo mítico; visión de la sociedad-visión individual; cordura - locura), disonancias cuya tensión genera el movimiento de la novela. El punto de partida será siempre racional. Como habíamos se- 
ñalado, los límites de la razón son explorados por conducto de la razón. Sin embargo, ésta puede ser cuestionada — desde el delirio - cuando se rebasan esos límites. La realidad racional sólo es una, las realidades delirantes son infinitas. Merced a los encantamientos todo es posible: toda la coherencia de una estructura racional puede estar sustentada sobre un ápice de locura; a su vez, todo un mundo delirante puede partir de la realidad objetiva. El delirio y la razón tienen sentido por los encantamientos, que son como un lente que transforma la realidad creando una o varias realidades que pueden tener un sentido delirante o racional. Los juegos de encantamientos acaban por sugerirnos que la realidad racional puede estar encantada. Sospechamos no que la realidad sea irreal como advierte Paz, sino que la realidad racional es tan ilusoria y efímera como el mundo delirante. Quizás esto — en partees lo que el narrador quiere sugerirnos en el primer párrafo del capítulo diez: la realidad es un "engaño a los ojos", no hay mayor locura que la realidad.

\section{El tiempo}

El Quijote es "palabra en el tiempo", constante metamorfosis, espejo de nuestro mundo temporal, reflejo de nuestra condena. Los personajes son porque dejan de ser, se van deshaciendo conforme se construyen. Su riqueza interior va y viene por los laberintos de la retórica expresando sobre todo ambigüedad y contradicción. La contradicción es tensión y movimiento; la ambigüedad caracteriza nuestra percepción del mundo. El contrapunto resuelve la contradicción porque esencialmente es temporal. La consonancia vuelve a transformarse en disonancia como un desengaño que se transforma nuevamente en un engaño. Este proceso diacrónico dibuja y desdibuja la mayoría de los encantamientos. Refiriéndose a ellos don Quijote advierte: "Podría ser que con el tiempo se hubiesen mudado de unos en otros" (I, 49, 501), enfatizando el hecho de que el juego de los encantamientos es, sobre todo, temporal. La mudanza de una cosa en otra sólo puede darse en el tiempo.

Ahora bien, en la novela podemos distinguir entre un tiempo cronológico (racional), diacrónico, y un tiempo mítico, sincrónico. Este último 
es el de la aventura. Cuando don Quijote se lanza a una aventura se detiene el reloj y nos adentramos en el tiempo sin tiempo del mito. Durante la aventura todo el tiempo es el presente, el tiempo de la metáfora y del sueño. Don Quijote no sólo se aleja de la realidad racional sino también del tiempo convencional. "A sólo Dios está reservado conocer los tiempos y los momentos — advierte don Quijote-, y para Él no hay pasado ni porvenir, que todo es presente" (II, 25,748). Este tiempo divino se acerca al tiempo primordial (de acuerdo con María Zambrano) que no tenía medida, cuando la Totalidad se percibía - simultáneamente- en un solo instante. Así, don Quijote transforma los segundos en instantes en los que el tiempo se contrae o se dilata sin medida.

El tiempo cronológico y el tiempo mítico (ya lo habíamos mencionado) al enfrentarse crean una tensión contrapuntística que casi siempre se resuelve en la consonancia del tiempo cronológico. Los encantamientos muchas veces están relacionados (como veremos) con este movimiento. Es el tiempo (sobre todo el tiempo) el que se encarga de encantar y desencantar el mundo. "El tiempo, descubridor de todas las cosas, no se deja ninguna que no la saque a la luz del sol, aunque esté escondida en los senos de la tierra" (II, 26, 750).

\title{
La verdad
}

\author{
El que tiene razón siempre \\ no siempre tiene verdad: \\ muy pocas veces la tiene. \\ José Bergamín, Canto rodado
}

"Es menester tocar las apariencias con la mano para dar lugar al desengaño," dice don Quijote al toparse con una carreta de comediantes (II, $11,627)$. Se refiere a los disfraces y máscaras que éstos llevan (curiosamente esta vez, cuando "la realidad" está disfrazada, nuestro Caballero la acepta tal cual es). En el siguiente capítulo nos dirá que la comedia es un espejo del mundo y que "ninguna comparación hay que más al vivo nos represente lo que somos" (II, 12, 631). La imagen del espejo (con solo invertir los términos) devela la posibilidad de que el mundo 
sea una comedia, tal como lo advierte don Quijote más adelante (en el sentido calderoniano de El gran teatro del mundo), donde cada uno desempeña su papel. En este teatro, donde una máscara nos hace personas, nos preguntamos si tiene sentido la frase que abre este párrafo, es decir, si al tocar las apariencias en nuestro mundo no descubrimos también que son un disfraz.

"Se percibe lo yacente tras lo aparente" (Hacia Cervantes, 325), nos dice Américo Castro refiriéndose al estilo del Quijote; es un estilo - sentimos - que nos va despojando de certezas; que "invierte las perspectivas, provoca la variedad de las miradas y hace triunfar la libertad de los personajes, revelando otra verdad del mundo" (Redondo, Otra manera, 484). Una verdad yacente detrás de las máscaras, que apenas tocamos cuando se desvanece. Una verdad que surge cuando rasgamos el velo del parecer y descubrimos el Ser. Un delirio que se esconde tras la razón. Una escultura que se va despojando de su forma precisa. "Hay una realidad de encubrimiento que no es pura mentira pero que escamotea y disfraza una 'verdad desnuda" (Caraso, "Canto rodado", 130-131). "Sancho, que si a los oídos de los príncipes llegase la verdad desnuda, sin los vestidos de lisonja [advierte don Quijote], otros siglos correrían" (II, 2, 563).

Nuestro Caballero va en busca de la verdad (el caballero andante ha de ser "mantenedor de la verdad, aunque le cueste la vida el defenderla” (II, 18, 683), y la descubre en la imaginación, en la metáfora, en el delirio. Luis Cernuda apunta que Cervantes "sabe cómo hay verdades que sólo a través del delirio se manifiestan por primera vez a los hombres" ("Cervantes", 242-243). En el mundo delirante no hay formas, hay transformaciones: los desengaños pueden ser engaños; las aceñas, fortalezas; las ventas, castillos, y una polvareda puede ocultar ejércitos invisibles. En el delirio hallamos esa verdad que entraña todas las maneras de entender el mundo y a la vez sólo una, la idea de unidad primigenia, verdad desnuda, un solo ser en perpetua metamorfosis.

"En la locura — nos dice Ciriaco Morón- encontró Cervantes la expresión de su verdad" (Nuevas meditaciones, 149). La locura abre una puerta al mundo de las analogías, donde los entes más disímiles se corresponden. Allí el sin sentido cobra sentido, y la alucinación no es más que otro punto de vista. 
Podríamos confundir la realidad (o más bien las realidades) con la verdad, pero esta última entraña algo mucho más profundo, que va más allá de un punto de vista o de una visión del mundo. Entraña, en un sentido ontológico, la relación entre el estar y el ser (espacio y tiempo). La palabra poética va descifrando esta relación a través del tiempo, gracias al tiempo. "El tiempo, digo [apunta Jorge Pérez de Tudela al referirse al Quijote], será también aquí el agente de una paulatina revelación de la verdad" ("Tiempo del Quijote", 114). Percibir con el ser es percibir con el tiempo, ser dejando de ser, tiempo que desnuda la verdad, verdad desnuda que no es otra cosa que vivir de verdad; "y ese, tiempo de lo vivido, no es otro que el rapidísimo paso, el de la casi instantánea transformación de un contrario en otro" (114), constante oscilación, contrapunto a dos voces. Incesante metamorfosis que es la vida. "Mas lo nuevo en el Quijote [advierte Américo Castro] consistió en hacer valer como verdadero lo auténticamente fundado en una experiencia vital, y no lo determinado por un análisis racional" (Hacia Cervantes, 384). Una de las intenciones centrales de Cervantes — apunta el mismo Américo Castro- consistía en presentar la oposición entre lo vital y lo racional "como un problema de infinita amplitud" (Pensamiento de Cervantes, 176). Si la verdad es esencialmente vital, este problema podría llevarnos a una oposición entre la verdad y la razón. Un contraste que cobra fuerza si pensamos en una verdad poética (que necesariamente es vital tanto en el texto como en el mundo), cercana al delirio; es decir, cercana a la experiencia del mundo como un todo.

Ahora bien, esta verdad poética entraña una antítesis en sí misma: por un lado es total vitalidad, por otro expresa la máxima consonancia de la muerte. Cuando don Quijote se refiere a la comedia de este mundo nos dice que "en llegando el fin, que es cuando se acaba la vida, a todos les quita la muerte las ropas que los diferenciaban, y quedan iguales en la sepultura" (II, 12, 631). Si el delirio rasga el velo de la apariencia, la muerte nos arranca la máscara. El mundo es como un juego de ajedrez, "mientras dura el juego cada pieza tiene su particular oficio, y en acabándose el juego todas se mezclan, juntan y barajan" (631-632). Acaso acabándose el juego morimos o soñamos, perdemos la razón, encontramos la verdad. 


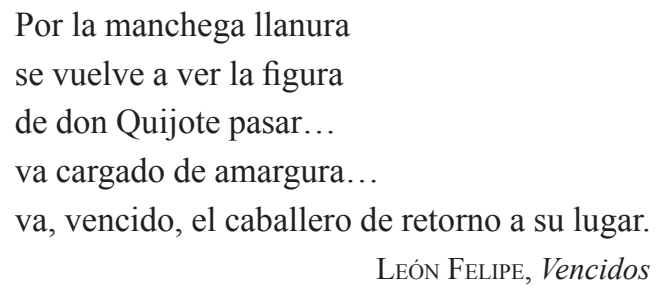

En el capítulo dieciocho de la segunda parte, Lorenzo, hijo de don Diego de Miranda, le pregunta a don Quijote: “¿Qué ciencias ha oído?”; nuestro Caballero le responde que "la de la caballería andante $[. .$.$] que$ es tan buena como la de la poesía, y aun dos deditos más". Enseguida le dirá que la caballería "encierra en sí todas o las más ciencias del mundo" (II, 18, 682). Dos capítulos antes, en una conversación con don Diego de Miranda, en defensa de la poesía don Quijote nos dice: "Es como una doncella tierna y de poca edad y en todo extremo hermosa, a quien tienen cuidado de enriquecer, pulir y adornar otras muchas doncellas, que son todas las otras ciencias" (II, 16, 666). Ambas "disciplinas" (la caballería y la poesía) tienen para don Quijote el carácter de reunir a todas las ciencias. Si comparamos la poesía (en sus sentidos antiguo y moderno) con la especial caballería quijotesca, nos sorprenden otras coincidencias. Empecemos por enfatizar el hecho de que para don Quijote la poesía está casi a la altura de su profesión. Ambas tienen un carácter universal, de acuerdo con la idea renacentista de que la poesía "comprende y trata de toda cosa que cabe debajo de la imitación". 2 Don Quijote lleva la poesía al camino de la aventura, y más allá de la imitación intenta transformar con ella el mundo. Así se acerca al sentido etimológico del término (poiesis, hacer), que no sólo implica creación, sino también acción. Intentamos esbozar de qué manera la verdad poética significa vivir; la poesía de verdad — en su sentido mítico - nos deja revivir, rebasa la hoja de papel y nos lleva a su origen antes de la palabra. Lleva nuestros sentidos al tiempo de la infancia, al primer aroma, al primer color, cuando un mundo poético se revelaba con sólo

${ }^{2}$ Pinciano, apud Américo Castro, El pensamiento de Cervantes, 42. 
sentir. Este mundo se apodera de nuestro Caballero cuando intenta crear otra realidad con sus ojos alucinados. Don Quijote — nos dice Pedro Salinas - intenta "conquistar un espacio físico para lo que lleva dentro, para su espacio psíquico" ("Cervantes", 139); consigue ganarle terreno a las fronteras de la realidad racional que lindan con el territorio del delirio. Éste aparece, en su sentido metafórico, cuando el mundo interior entra en contacto con la realidad, esa interacción involucra una analogía inevitable que ilumina el mundo. El loco y el poeta se valen de la metáfora para transformar la realidad racional, sólo que el poeta crea dentro de los límites que la misma razón le ha proporcionado, mientras que el loco no conoce esos límites. El poeta intenta, dentro de sus límites, que la palabra se convierta en experiencia vital, el loco cree que su mundo interior (que se ha apoderado de la realidad) es la vida. Ambos, a partir de la identidad, borrando las líneas de la semejanza, pueden integrar los opuestos dentro de un todo.

Foucault compara al poeta con la percepción que se tenía del loco hasta fines del siglo XVIII; nos dice que el loco es diferente en cuanto no conoce la diferencia, para el loco "todos los signos se asemejan y todas las semejanzas valen como signos. En el otro extremo cultural [continúa Foucault], pero muy cercano por su simetría, el poeta es el que, por debajo de las diferencias nombradas y cotidianamente previstas, reencuentra los parentescos huidizos de las cosas [...] oye otro discurso, más profundo, que recuerda el tiempo en que las palabras centelleaban en la semejanza universal de las cosas, la Soberanía de lo Mismo [...] borra en su lenguaje la distinción de los signos" ("Don Quijote", 56). El poeta — creemos - oye la música silenciosa de las cosas, que tiene un sentido primordial, en el que la identidad del mundo se percibe con todos los sentidos, en especial con el oído. Acaso el loco es poseído por esta música que en la simultaneidad de un instante borra los nombres y los límites.

Ya en la cultura occidental moderna, advierte Foucault un "enfrentamiento de la poesía y la locura [...]. Es la marca de una nueva experiencia del lenguaje y de las cosas". Creemos que el Quijote es precursor de esta nueva experiencia, en la que se cuestiona la relación convencional entre la palabra y la cosa. En este sentido don Quijote, como un poeta moderno, vuelve a nombrar al mundo. Ambos, el poeta y el loco — nos dice Foucault - encuentran "un saber en el que, por una ruptura esen- 
cial en el mundo occidental, no se trata ya de similitudes, sino de identidades" (56). En un mundo fragmentado don Quijote va por el "camino de aunar creencias y actos, ideas y cosas" (Salinas, "Cervantes", 87), transformando semejanzas en identidades. "Ante nuestras almas despedazadas, de seres divididos - advierte Pedro Salinas-, él surge como el caballero de la unidad" (87).

De acuerdo con Américo Castro don Quijote es "el personaje-poeta", un ejemplo de su poesía es él mismo "metaforizando en gigantes los molinos" (Hacia Cervantes, 316). La diferencia entre el poeta y don Quijote - apunta Pedro Salinas - es que nuestro Caballero no ha creado su mundo "para contemplarlo, sino para vivirlo" ("Cervantes", 140). Quizás el poeta puede vivir su mundo — creemos — con la misma intensidad que nuestro Caballero, su materia a fin de cuentas es la vida; sin embargo el poema queda enmarcado en la ficción, en los márgenes de la hoja de papel. Cervantes nos invita a sacar a su personaje de la hoja de papel, y a ir construyendo con él un mundo poético que en nuestra imaginación rebasa la ficción. Si el poeta va construyendo su camino con los versos, don Quijote crea el poema con su camino. Sus lecturas adquieren en él tal intensidad que se desbordan en el mundo; pero ese mundo a su vez, como las cajitas chinas, está enmarcado en el libro.

La intención de la literatura ha llegado en nuestro Caballero a sus máximas consecuencias. A tal punto ha conseguido embriagarlo que ha perdido el sentido de la realidad racional, también del tiempo cronológico. Esta intención no sólo ha transformado en personaje a su lector, sino que este lector es capaz de crear un mundo en el que la imaginación y la realidad desnudan la hoja de papel. "La locura de don Quijote es creación pura; rotura de amarras con el pasado y el presente. En este punto Cervantes nos ha dado la tipología de los grandes creadores" (Morón, Nuevas meditaciones, 209).

Don Quijote es un creador que construye su poema desde la derrota, defendiendo siempre a los que llevan las de perder. Una y otra vez es derrotado, una y otra vez vuelve a levantarse, porque el misterio del poema se revela en un instante a la sombra de los vencidos. En el poema de Alberti, ${ }^{3}$ la paloma podría simbolizar el espíritu del poeta que se

${ }^{3}$ Un fragmento de este poema aparece en el primer epígrafe de este trabajo. 
enfrenta a una realidad racional, misma que siempre lo desengaña; en su sueño poético el mar es el cielo, el mar está encantado. El resultado del pensamiento metafórico — en el poema de Alberti- es el desencuentro amoroso: "Ella se durmió en la orilla. / Tú, en la cumbre de una rama". La peor derrota, la consecuencia de todas las derrotas, es perder a la dama: Dulcinea está encantada, ha sido transformada en una rústica labradora. La melancolía nace de la mujer idealizada. Dulcinea intocable, hecha con la materia de los sueños, ha sido despojada de su belleza imaginaria. Don Quijote insiste en que es ella la que está encantada, como si se tratase de la misma realidad que una y otra vez derrota a los sueños delirantes.

\section{Los molinos de viento}

Lo primero que nos presenta el narrador en el primer párrafo de este capítulo es la realidad racional: "Descubrieron treinta o cuarenta molinos de viento" (I, 8, 75), que es el punto de partida de todo encantamiento y toda aventura. El girar de las aspas (que imaginamos) evoca tal vez un tiempo cronológico que sustenta la realidad. La perspectiva del narrador (aunque dude del número de molinos) y la realidad que representa están en perfecta consonancia. En un breve diálogo entre don Quijote y Sancho - previo a la aventura - puede apreciarse el sentido contrapuntístico entre el delirio y la razón (don Quijote sostiene que se trata de gigantes, mientras Sancho insiste en que son molinos); pero la disonancia central (que sustenta la construcción contrapuntística del episodio) aparece cuando don Quijote da espuelas a su caballo para iniciar la aventura (I, 8, 75). En ese momento parece que el tiempo cronológico se detiene y nos adentramos en el tiempo sincrónico del mito. El antagonismo entre el delirio y la razón adquiere la máxima tensión. Nuestro Caballero arremete contra la realidad racional y al mismo tiempo desborda su mundo interior sobre ella. La lucha se sostiene en la sincronía de una metáfora: los molinos son gigantes.

"La sustancia del Quijote - ha escrito Jorge Pérez de Tudela-, en efecto, no es otra que la tensión. Reflexiona sobre los opuestos, se construye sobre opuestos, y advierte, más que nada, de la dura lucha 
de la oposición" ("Tiempo del Quijote", 112-113). La disonancia es tensión, inestabilidad, contradicción, ambigüedad, temblor, metáfora en movimiento. Dura un instante, una medida de eternidad, hasta que nuestro Caballero termina "rodando muy maltrecho por el campo" $(\mathrm{I}, 8,76)$ después de haber embestido con su lanza un aspa del molino. De acuerdo con Ortega y Gasset ha triunfado la materialidad, estamos desilusionados (el autor emplea el término en su doble acepción de perder las ilusiones y desengañarse). La disonancia se resuelve en consonancia, regresa el tiempo cronológico, nuestros personajes regresan al camino. Desaparece el término imaginario de la metáfora. Don Quijote reconoce los molinos de viento pero sólo si están encantados: "Y es así verdad, que aquel sabio Frestón [...] ha vuelto estos gigantes en molinos, por quitarme la gloria de su vencimiento" (I, 8, 76). El tiempo cronológico le ha devuelto su apariencia a los molinos, pero para don Quijote es sólo eso, apariencia que esconde la verdad. En el episodio del barco encantado, don Quijote le dice a Sancho: "Y ya te he dicho que todas las cosas trastruecan y mudan de sus ser natural los encantos. No quiero decir que las mudan de en uno en otro ser realmente, sino que lo parece" (II, 29, 776). Es decir que el Ser no cambia, cambia el parecer a lo largo del tiempo. Para don Quijote es la realidad racional (una apariencia) la que a fin de cuentas está encantada. Generalmente en los procesos de encantamientos don Quijote acaba por ver la realidad, pero sólo puede aceptarla si está encantada. El resultado es una trasposición del término real y el término imaginario de la metáfora, donde el término real, los molinos de viento, acaba por ser el término imaginario en la mente de don Quijote. En el tiempo sincrónico don Quijote encuentra el sentido de la metáfora, su verdad, el delirio; en el tiempo diacrónico nuestro Caballero ve la realidad racional, pero no puede aceptarla, y nos invita a pensar que es sólo apariencia.

De acuerdo con Octavio Paz la vuelta al tiempo cronológico afianza la realidad racional: "Los molinos son gigantes un instante, para luego ser molinos con mayor fuerza y aplomo" ("Ambigüedad de la novela", 223). Esta idea no es del todo incompatible con lo que hemos planteado, acaso sugiere que la realidad racional necesita del delirio para afianzar su esencia. 
El tiempo y la metáfora (que entraña el delirio y la razón) aparecen en el Quijote articulados en procesos contrapuntísticos similares a los que hemos intentado esbozar: Manuel Durán señala que "es precisamente la inestabilidad de las antítesis la que introduce la confusión y la movilidad en el mundo cervantino" (La ambigüedad en el Quijote, 118). Pérez de Tudela en el mismo sentido que Paz apunta que "lo contradictorio, la dualidad, no sólo no desmienten, sino que dan fuerza a la unidad" ("Tiempo del Quijote", 112). Luis Cernuda sostiene que "a Cervantes le atraen los extremos [...] pero esos extremos vuelve a unirlos mirando la vida con una casi divina serenidad" ("Cervantes", 238). Herbert Read ha escrito que el arte es un proceso dialéctico, que implica "la resolución de contradicciones y ambigüedades". ${ }^{4}$ Manuel Durán completa la idea advirtiendo que se trata de una resolución parcial (La ambigüedad en el Quijote, 13). Nuestros personajes vuelven al camino, al tiempo cronológico; se resuelve la tensión de una metáfora, se reconcilian los opuestos. La consonancia dura lo que dura el camino, hasta llegar de nuevo al tiempo de la aventura.

\section{La polvareda}

Podemos encontrar todos los rostros en las formas de las nubes. "Solía Leonardo da Vinci poner a sus alumnos frente a una tapia con el fin de que se acostumbraran a intuir en las formas de las piedras, en las líneas de sus junturas, en los juegos de sombra y claridad, multitud de formas imaginarias. Platónico en el fondo de su ser, buscaba en la realidad Leonardo sólo el paracleto, el despertador del espíritu" (Ortega y Gasset, Meditaciones del Quijote, 220). Don Quijote ve venir la polvareda $(\mathrm{I}, 18,156)$ con su movimiento que despliega todas las formas y sólo una, ocultando la apariencia, velando un misterio, invitándolo a soñar lo que hay detrás. Porque el mundo se sostiene en un secreto que nuestro Caballero descubre al inventar otro mundo cubierto por el polvo. "El polvo es la materia de su poemática invención" (Salinas, “Cervantes", 129). Despierta su espíritu para que pueda volver a nom-

\footnotetext{
${ }^{4}$ Herbert Read, apud Manuel Durán, La ambigüedad en el Quijote, 13.
} 
brar al mundo. En la imaginación de nuestro Caballero, "el caos, polvo sin formas, se hará mundo" por medio de la palabra. "Don Quijote, alma pura y primitiva, tiene confianza en la palabra, en su poder de realizar" (129). Utiliza uno de los procedimientos poéticos más antiguos, la enumeración. Con ella expresa la sensación de simultaneidad. Todos los caballeros y "gentes de diversas naciones" que nombra se dibujan en un mismo instante. La enumeración le brinda a cada uno de ellos un lugar equivalente dentro de un todo que se oculta detrás del polvo. "Ahí le tenemos — nos dice Pedro Salinas - ya presto a ponerle nombres al polvo. ¿Pero semejante voluntad, no es idéntica a la del poeta?" (“Cervantes", 131). El sentido poético de la enumeración tiene que ver con su poder integrador en el tiempo y en el espacio. Por medio de la enumeración el poeta consigue llevar al lenguaje - que por naturaleza es sucesivo - la sincronía descubierta por una mirada. Don Quijote va más allá, su mirada sueña; su sueño entraña el arte de nombrar al mundo. La polvareda que cubre la realidad descubre otra realidad. El polvo puede simbolizar el velo de la apariencia; acaso detrás está el Ser, la verdad, el sueño, dos ejércitos invisibles entre todas las formas del polvo.

Borges nos invita a pensar que la literatura puede prescindir del espacio, pero no del tiempo. Los ejércitos que don Quijote crea viven en el tiempo, por ello son menos reales, pero más verdaderos. Están hechos con el material de los sueños.

Pedro Salinas sugiere que el altillo —al que suben don Quijote y Sancho para ver los ejércitos - representa la altura con la que el poeta observa el mundo a la hora de crear: "El poeta es un hombre como todos [...] Pero que se le anuncie el afán de poetizar, y habrá de separarse, alzándose de sus prójimos. Lo poético siempre ha llevado una connotación de altura" (131).

Don Quijote sube al altillo y empieza a recitarle a Sancho esas dos enumeraciones que entrañan, cada una, un mundo; que se elevan sobre las manadas de carneros y ovejas. Hasta este punto don Quijote es un poeta, pero en cuanto pone "la lanza en el ristre" para embestir a los rebaños, y enfrenta su mundo delirante contra la razón (que estructura la realidad), se transforma en el Caballero de la Imaginación, y va a defenderla, una y otra vez, a pesar de los palos y las pedradas. 
En este caso dos pedradas - entre muchas - de los pastores consiguen derribarlo. La tensión contrapuntística entre la razón y el delirio ha resuelto en consonancia, regresamos a la realidad y con ella a la derrota. El tiempo mítico se transforma en tiempo cronológico. Don Quijote desde el suelo advierte que un encantador "ha vuelto los ejércitos en manadas de ovejas". De nuevo el término real aparece en la mente de don Quijote como el término imaginario. Es la realidad racional la que está encantada.

\section{La cueva de Montesinos}

Augustin Redondo en un capítulo dedicado a la cueva de Montesinos habla de una parte "ante-histórica" del hombre; si uno se deja llevar por ella puede alcanzarse "el lenguaje y hasta la experiencia de un paraíso perdido" (Otra manera, 405). Lo primero que dice don Quijote, después del descenso a la cueva, cuando vuelve en sí ("Dios os lo perdone, amigos, que me habéis quitado de la más sabrosa y agradable vida y vista que ningún humano ha visto ni pasado" (II, 22, 722), demuestra el sentido paradisiaco de su experiencia. El paraíso, al cual se refiere Redondo, nos remite a un mundo primordial, que se acerca al mundo de los sueños. En ambos mundos se pierden las coordenadas del espacio y del tiempo. El mismo Redondo menciona una "fase paradisíaca del hombre primordial" (Otra manera, 405), que todos llevamos dentro y que recordamos con el olvido, en duermevela, en los sueños despiertos.

Don Quijote despierta en un sueño, un sueño dentro de un sueño, "en la mitad del más bello, ameno y deleitoso prado que puede criar la naturaleza, ni imaginar la más discreta imaginación humana" (II, 22, 723). La idea de un mundo primordial entraña siempre la comunión del hombre con la naturaleza. Este prado, que es el más bello que pueda imaginarse, evoca el tiempo sin tiempo, cuando en un descanso del camino, el hombre y la naturaleza eran uno solo. Es fundamental que aparezca como un preámbulo a todas las visiones de la cueva, porque enfatiza el sentido paradisíaco de la experiencia. Es la antesala de un mundo delirante, alejado de la realidad racional, donde imágenes fantásticas se sucederán unas a otras, a partir de la mirada de don Qui- 
jote: en un alcázar de cristal aparece Montesinos ya anciano con un rosario de "cuentas mayores a medianas nueces"; vemos el sepulcro de Durandarte hecho de mármol, en el que el muerto se queja, suspira y hasta recita un romance; Guadiana, su escudero, ha sido transformado en un río melancólico; a través de una pared de cristal de aquel alcázar vemos una procesión "de hermosísimas doncellas, todas ellas de luto, la última es Belerma que lleva el corazón de Durandarte; en el prado ameno aparece aquella labradora que en capítulo décimo de la segunda parte, Sancho había convertido en Dulcinea”. Este mundo onírico crea una tensión contrapuntística al contrastarse con la realidad racional, que aguarda fuera de la cueva, misma que de acuerdo con Augustin Redondo, forma parte de un ritual iniciático, es "el sitio de la iniciación”, que "está apartado de los lugares de la vida corriente [...] se trata de un espacio diferente a lo ordinario" (Otra manera, 404-413); un espacio que delimita físicamente las fronteras entre la razón y el delirio. Más allá de la parte cómica que pueda tener el episodio, la cueva es un espacio sagrado — en su sentido primordial — donde el mundo de la locura halla su cauce. Sea sueño o alucinación, lo que ocurrió en la cueva permanecerá en ese espacio delirante, sin que la realidad racional pueda desengañarnos; es por ello que Cide Hamete anota en los márgenes que la aventura de la cueva es la única que va "tan fuera de los términos razonables" (II, 24, 734). En este sentido el contrapunto entre el tiempo de la aventura y el cronológico aparecerá marcado - por primera vez-en forma explícita cuando Sancho le dice a su amo que sólo estuvo en la cueva "poco más de una hora" (II, 23, 729), mientras don Quijote afirma haber estado tres días.

El sentido paradisiaco de un mundo primordial que no distingue sueño y vigilia se dibuja en un espacio sagrado y en el tiempo sin tiempo del mito. A través de los cristales del alcázar las imágenes delirantes se transparentan a la luz de los sueños.

\section{El retablo del Maese Pedro}

Los bastidores del retablo, hacia adentro, enmarcan el espacio de la imaginación, del sueño, la aventura y el mito, frente a la realidad racional 
que está fuera (Ortega y Gasset, Meditaciones del 'Quijote', 209-210). Desde adentro se escucha el nombre de Sansueña (Sajonia), que evoca la región de los sueños. Afuera don Quijote, poco a poco, se olvida de su condición de espectador. Dentro del retablo se representa un sueño como un espejo de su mundo interior. La novela es también un retablo que guarda otro retablo. En ella el teatro guiñol ha logrado su máxima intención: el espectador olvida los límites que marcan los bastidores. El delirio borra las fronteras entre la ficción y la realidad. La realidad puede estar adentro o afuera, es ella la que está encantada, Dulcinea, una región del sueño, la realidad. Don Quijote desenvaina su espada, se coloca junto al retablo, y empieza a despedazar a los títeres. Se trata de un intento alucinado por integrar lo que la razón había escindido. Don Quijote intenta transformar el mundo en un teatro y ahora quiere transformar el teatro en un mundo.

\section{Cierre}

La tensión contrapuntística entre el delirio y la razón estructura y desestructura la novela, y genera el movimiento de las múltiples voces, que a su vez inventarán realidades y sueños.

Parece que la novela se escribe conforme la leemos, los personajes se hacen y deshacen como las voces del contrapunto que ya resurgen en otro pulso. Merced al tiempo no hay nada que sea igual a sí mismo, todo es mudanza de una cosa en otra, desengaño que se transforma en engaño, como consonancia en disonancia. No podemos asir un ápice de tiempo, ni una espada surca dos veces el mismo aire. Un instante encantado le cede el paso a un segundo que desencanta. El tiempo de la aventura se enfrenta al cronológico, y nos ilusiona y desilusiona. En la profundidad del tiempo aparece la verdad como el Ser detrás de la apariencia que ya se desvanece. La metáfora nos recuerda un mundo primordial donde todo era identidad, el mundo del Ser. El poeta y el loco encuentran esta identidad en una metáfora. El loco intenta verter su mundo metafórico en la realidad racional, ganarle un espacio físico a la imaginación, y allí se topa con una estructura que una y otra vez lo derrota, pero su intento nos invita a preguntarnos hasta dónde llegan los 
límites de la razón, hasta dónde los del delirio, hasta dónde la realidad racional sería posible sin la locura. En la oscuridad y el silencio los opuestos se reconcilian, y las piezas de ajedrez se guardan en la cajita de su tablero.

\section{REFERENCIAS}

CARAso, Joel, "Canto rodado: Bergamín angélico, duendístico y musarañero", en En torno a la poesía de José Bergamín, Nigel Dennis (ed.), Lleida, Pages Editors / Universitat de Lleida, 1995, 113-152.

Castro, Américo, El pensamiento de Cervantes [1925], Barcelona, Editorial Noguer, 1980.

CAstro, Américo, Hacia Cervantes [1957], Madrid, Taurus, 1967.

Cernuda, Luis, "Cervantes", en Poesía y literatura, I y II, Barcelona, Seix Barral, 1975, 221-246.

Cervantes, Miguel de, Don Quijote de la Mancha, Madrid, Real Academia Española, Asociación de Academias de la Lengua Española, 2004.

DurÁn, Manuel, La ambigüedad en el 'Quijote' [1960], Jalapa, Universidad Veracruzana, 1981.

Foucault, Michel, "Don Quijote", en Las palabras y las cosas, trad. Elsa Cecilia Frost, México, Siglo XXI, 2008, 53-56.

Guillén, Claudio, "Cauces de la novela cervantina: perspectivas y diálogos", en Don Quijote de la Mancha, Madrid, Real Academia Española, Asociación de Academias de la Lengua Española, 2004, 1145-1152.

Morón Arroyo, Ciriaco, Nuevas meditaciones del 'Quijote', Madrid, Gredos, 1976.

Ortega y Gasset, José, Meditaciones del 'Quijote’[1914], México, Rei, 1987. PAz, Octavio, "Ambigüedad de la novela", en El arco y la lira, La casa de la presencia (Poesía e historia), Obras completas (t. I), México, Fondo de Cultura Económica, 1999, 33-288.

PAz, Octavio, "Los hijos del limo", en Los hijos del limo, La casa de la presencia (Poesía e historia), Obras completas (t. I), México, Fondo de Cultura Económica, 1999, 365-380.

Pérez de Tudela, Jorge, “Tiempo del Quijote, tiempo de Cervantes, tiempo del lector", en Edad de Oro (xv), 1996, 111-124.

Redondo, Augustin, Otra manera de leer el 'Quijote', Madrid, Castalia, 1998. Reyes, Alfonso, "El enigma de don Quijote", en Alfonso Reyes lee 'El Quijote', México, El Colegio de México, 2008, 57-58. 
Salinas, Pedro, "Cervantes", en Ensayos de literatura hispánica, Madrid, Aguilar, 1961, 75-142.

Spitzer, Leo, "Perspectivismo lingüístico en El Quijote", en Lingüistica e historia literaria, Madrid, Gredos, 1955, 161-255.

Zambrano, María, El hombre y lo divino [1955], México, Fondo de Cultura Económica, 2001. 